\title{
APRESENTAÇÃO
}

\section{A história e os corpos: imagens de um mundo em guerra}

Frederico Canuto

Universidade Federal de Minas Gerais, Belo Horizonte, Minas Gerais / Brasil fredcanuto@gmail.com

Fernando Resende

Universidade Federal Fluminense, Niterói, Rio de Janeiro / Brasil fernandoaresende1501@gmail.com

Ao propor o tema da chamada deste número do Cadernos Benjaminianos - Urbanismo e Guerra - lançamos uma série de referências primeiras que procuraram abordá-lo de maneira diversa e o mais aberta possível, pensando-o tanto como conflito destrutivo quanto também produtivo no contexto das cidades e espaços urbanos.

O Urbanismo, como um dos recortes conceituais da proposta, foi posto como operador inicial visto que é nos espaços urbanos sejam eles as cidades ou o campo -, que a vida acontece, tanto em sua excepcionalidade, como em sua monotonia diária. Tomando-o não como a ciência que cria um modo de intervir sobre a cidade, mas uma que a considera e a pensa como espaço de criação de modos específicos de viver no mundo, tal conceito é vital para se começar a pensar a relação entre estética, política e cotidiano seja pelas imagens ou pela vida vivida. Não coincidentemente, é a cidade e a experiência metropolitana, uma das preocupações centrais do pensamento benjaminano: lócus do capital e de suas contradições e potencialidades insurgentes. 
Tendo tal espacialidade como centralidade, a ideia de estetização da política desenvolvida por Benjamin, em $A$ obra de arte na era de sua reprodutibilidade técnica, no contexto da ascensão do fascismo e de sua relação com um conflito armado entre nações à época ainda não instalado tornou-se mote para uma discussão da violência, destruição e precarização da vida. Tomando estes como traços de uma idiossincrática vida metropolitana no seio da metrópole novecentista e nos espaços das cidades desiguais do século XX e XXI, eles são também desdobramentos de uma guerra particular que iniciada como resolução de conflitos políticos, torna-se política do cotidiano e dos corpos. Concordando então com Michel Foucault Em defesa da sociedade (2005), "a política é a continuação da guerra por outros meios", pois interioriza a guerra e a transforma em cálculo, em biopolítica, em gestão de riscos.

Assim, a guerra aparece como segundo recorte conceitual. Como contraponto, e de modo a expandir a própria noção de guerra como controle, gestão e cálculo, apontamos a ideia de conflito numa perspectiva baseada no pensamento da geógrafa Irit Rogoff. Para esta autora, em Terra Infirma: geography's visual culture (2006), os conflitos, particularmente os de longa duração, impõem um desafio não somente aos sujeitos que os vivem no seu cotidiano, mas também, muito especialmente, aos que têm como ofício refletir e procurar entender seus modos de produção e desdobramentos. Somos nós, pesquisadores, que nos vemos também afetados pela experiência de conflitos que alteram nossos modos de estar e pensar o mundo. Nos dias em que vivemos, quando o que se entende por guerra se conforma em uma pletora de conflitos territoriais, étnicos e religiosos, propõe a autora, nós nos vemos diante de "geografias exauridas"; fato que nos impõe reconhecer a falta de instrumentos para pensar e articular modos de conhecimento que nos fariam entender os conflitos na complexidade em que eles se dão.

Além de Rogoff, chamamos também atenção para Pierre Clastres no texto Guerra nas sociedades primitivas (2011), que pensa tal conflito como traço definidor de um modo particular de construir uma sociabilidade nas populações ameríndias. Fazendo o mesmo movimento de Deleuze, que em Mil Platôs (1997) articula as ideias de Clastres às máquinas de guerra no contexto do capitalismo e da produção do desejo, interessa-nos entender como a guerra pode se desdobrar numa violência que, antes de ser uma violação negativa dos corpos, é uma criação exponencial de outros. Um fato que nos ajuda a pensar a questão da multiplicação como 
sinônimo da boa política, a política da heterogeneidade, da diferença, do embate produtivo e criador, que ocorre a despeito, contra e dentro do Estado, como nos lembra Eduardo Viveiros de Castro numa entrevista no livro Encontros organizado por Renato Stutman (2003)

A proposta é, portanto, pensar cada artigo como uma mônada, em que Benjamin diz “(...) cada ideia contém a imagem do mundo. A representação da ideia impondo-se como tarefa, portanto, nada menos que a descrição dessa imagem abreviada do mundo". Nesse sentido, a partir de um recorte específico sobre o mundo, os artigos aqui apresentados produzem uma imagem que busca expor uma ideia e/ou um problema que se organiza em torno de um contemporâneo cuja "norma" é a própria experiência do conflito conforme nos diz Bernardo Miege em $O$ espaço púbico perpetuado, ampliado e fragmentado (1999).

Esta edição se torna, assim, um conjunto de imagens em que a violência, a resistência e a criação aparecem como traços indeléveis da relação entre os espaços do mundo, incluindo seus modos de fazer e experimentar as guerras e os conflitos. Por esta razão, entendemos que ela tornou-se uma mônada na qual o ano de 2013 reverbera. Tal momento não significa apenas "junho de 2013", mas um traço e/ou uma tradição de conflito(s) característico(s) de uma Modernidade que, tal como o anjo de Klee em famosa argumentação de Benjamin, é um acúmulo de ruínas composto pelos escombros do passado, estes que são vividos na materialidade da vida, nos espaços do cotidiano, seja em momentos excepcionais ou no dia a dia e esquecidos pela história dos vencedores. Ainda que o vento do progresso lance o anjo para o futuro, seus olhos olham o que ficou, desejando "acordar os mortos e juntar os fragmentos".

Neste sentido, 2013 seria um evento que tem filiações não apenas com outras regiões geográficas mas outros campos temporais. 2013 está próximo da eclosão dos movimentos Occupy, a partir da crise financeira de 2008, assim como dos conflitos por terra no Brasil e no mundo pois além de ser resistência contra a mercantilização da vida é invenção e multiplicação de outras formas de vivê-la. No entanto, tendo em vista os artigos que serão aqui apresentados, esta data também tem especificidade porque são dobras e desdobras de questões muito específicas brasileiras que vieram à tona e de modo visível como nunca antes: dos quilombos surgidos a partir da luta dos escravos, das imagens produzidas compartilhadas nas redes telemáticas em tempo real, das ocupações escolares. 
Sendo assim, a proposta é entender 2013 como um fantasma que às vezes aparece como objeto e outras como apontamento imprescindível para entendermos a relação histórica da ideia de guerra como produção de capitalismo e de desejo. Antes de ser um ano indecifrável, passado nas telas de computadores, televisores e nos corpos daqueles que estiveram e ocuparam as ruas, 2013, conforme sugerimos, torna-se um ponto nevrálgico relativo à de uma outra tradição, a de levantes, conforme pensado por Didi-Huberman.

O texto que abre a revista diz exatamente sobre a relação visível/ invisível entre o presente e o passado. Em "Perspectiva filosófica de Giorgio Agamben: a respeito da noção de recordação em Walter Benjamin", de André Carvalho de Moura, o que está em questão é justamente a presentificação e a escrita da história como tarefa. A pergunta que organiza tal texto é como se podem criar imagens que não representem o passado tal como ele pretensamente foi, mas como a ética, a poesia e a filosofia podem auxiliar, numa perspectiva bem singular que é a Agambeniana - de cumprir tal missão no interior e a partir da experiência histórica. Assim, esse é o fio que costurará todos os textos: uma discussão sobre representação, experiências e escrita da história.

A partir daí, tomando 2013 como um ponto de viragem, a primeira parte nos chama atenção para o que entendemos como Predisposições para um novo (mas o mesmo) 2013. Nesse sentido, a literatura, o cinema, o teatro e as artes, de modo geral, se apresentam nesta edição como formas e instrumentos centrais que ativam a compreensão das relações e dos problemas que propomos tratar entre urbanismo, guerra, história e conflitos.

Em "Literatura e política: Walter Benjamin e o caso Berlim Alexanderplatz", de Leonardo Francisco Soares, narrar a experiência metropolitana no contexto específico da república de Weimar usando o recurso da montagem dadaísta faz pensar a literatura em sua forma e conteúdo como modos de engajar-se politicamente no contemporâneo. Já em "Diálogos entre Walter Benjamin e Glauber Rocha: uma leitura alegórica de Terra em Transe e o mito fundador do Brasil", Juliana Rocha Franco faz uma leitura alegórica do filme de Rocha, apresentando-o como uma metáfora que coloca em cena o Brasil. Ao propor um diálogo entre Benjamin e Glauber Rocha, o artigo não só evoca outras leituras possíveis de um filme já amplamente discutido, como também nos faz ver como a história dos conflitos se reconfigura através e a partir do cinema. 
Em “A guerra por detrás da guerra - a batalha artística na Alemanha Nazista no período entre as grandes guerras", de Celina Borges Lemos e Danielle Amorim Rodrigues, discute-se historicamente o papel das duas grandes guerras, atribuindo sentidos e funções às suas entrelinhas, denominado "guerras por detrás das guerras". A arte e a arquitetura, em particular, são instrumentos de fundo que nos permitem avançar a discussão a respeito das relações entre guerra e estética. Tratase de pensar a estética, conforme aqui também propomos entender, como espaço de luta que ativa, inclusive e fundamentalmente, a posição dos corpos em determinados espaços e contextos.

Em "Ocupações de terra: constelações entre o Caldeirão de Santa Cruz do Deserto no Ceará e as ocupações urbanas de sem-teto da região Metropolitana de Belo Horizonte", os autores, Luiz Fernando Vasconcelos de Freitas, Joviano Gabriel Maia Mayer e Douglas Mosar Morais Resende, produzem uma reflexão muito interessante sobre memória e presente, evocando o problema da luta pela terra no Brasil. Conflitos territoriais, em sua dimensão micro, tornam-se complexos que nos instigam a pensar a respeito dos modos através dos quais as ocupações urbanas atravessam espaços e tempos. A produção de novas sociabilidades é uma questão central neste artigo e são com elas que os corpos produzem, no conflito, novas experiências.

E este exatamente o aspecto que nos leva aos artigos que estruturam a parte II da nossa edição, a que chamamos de Junho de 2013: das imagens e dos corpos. Sobre as imagens, dois textos discutem a questão. Em “E quando não houver ruínas?”, de Roberto Robalinho, a partir de um plano-sequência durante os protestos no Rio de Janeiro, se discute a representação fílmica e o potencial estético das imagens que querem fazer ver junho de 2013 pela experiência daquele que está lá. Já "Outras narrativas: imagens da Copa a partir do projeto Offside Brazil", Mariana Tidei oferece-nos uma discussão a respeito da disputa de narrativas no âmbito do conflito. O projeto Offside Brazil, na visão da autora, seria agente produtor de imagens dissensuais, e portanto agenciaria um novo campo, o que nos leva a pensar, uma vez mais, na dimensão da representação e da ação em torno de outros corpos produzidos e gestados no próprio conflito.

Sobre a dimensão dos corpos coletivos, em "Os corpos no espaço: confrontação ao simulacro democrático e resistência à estetização da política", de Pollyana Pereira Coelho, as imagens espetaculares cedem espaço 
para os modos de se fazer política advindos de 2013. Este texto usa as ocupações secundaristas ocorridas e tidas como lastro herdado deste ano para discutir os impasses e as ambiguidades da relação entre democracia direta e representativa, esta última um dos principais enfoques de crítica - "não nos representam".

E finalmente, no último conjunto de textos, pensando a dimensão que 2013 faz desdobrar para o futuro e afirma do passado, temos Pós Junho de 2013 ou o que sempre esteve aqui, cujos textos apontam para conflitos que se dão ora como traço de uma história da formação do Brasil e sua relação com o passado escravagista, ora como traço de uma ideologia desenvolvimentista que não cessa de apontar para o fim dos mundos.

Em "Matadouros à imagem da cidade", de Breno Luiz T. Silva, as asserções de Georges Battaille acerca do matadouro servem de mote para entender tanto a informalidade constituinte da realidade urbana como sua apropriação pelo capital, transformando o abjeto em templo do consumo - o shopping center. Tal movimento entre o que é construído à revelia vis à vis o que se transforma em objeto para ser consumido aponta para uma história de Belo Horizonte em que o erótico das ruínas e do que não está pronto é substituído pela limpeza estética, o que Benjamin aponta como facista em sua origem. $\mathrm{E}$ isso se conecta com "O som das escavadeiras", de Simone Cortezão, na medida em que o dispositivo que ativa a memória é o som. Em forma de elucubrações, ficcionais ou memorialísticas, as máquinas, de uma mineração globalizada - que vai do Oiapoque a Pequim - enterram o passado. Do sublime dos desastres ambientais, não um elogio mas uma crítica fabulativa em que paisagens da amnésia são descortinadas por textos e imagens.

Como contraponto aos matadouros e às escavadeiras, o texto "Cidades a contrapelo: por uma possibilidade de urbano", de Carolina de Castro Anselmo, apresenta-se a partir de um estudo relacional entre Benjamin e Boaventura de Souza Santos. Trata-se de um olhar renovado sobre os quilombos e as heranças de um passado colonial que podem apontar para o futuro sob novas formas de viver.

Ao retomarmos o movimento teórico do materialista benjamiano em suas Teses sobre a História - e de forma análoga ao que Engels e Marx pensaram a respeito da Primavera dos Povos no Manifesto Comunista de 1848, "um espectro ronda a Europa - o espectro do comunismo" - é possível dizer que um novo (mas o mesmo) espectro ronda agora o mundo. 
Não tendo mais a Europa como centro, mas um mundo globalizado e interconectado de centralidades dispersas e lideranças distribuídas num território alisado, o comunismo reaparece, não como uma revolução ou uma promessa, mas como aquilo que diz respeito a todos, seja como uma nova (e a mesma) história a ser escrita ou para apontar culpados - público e/ou coletivo - consentidos e incitados pelo Estado e mercado, muitas vezes em conluio, ou em novos regimes de economia política centrados numa democracia radical e numa solidariedade.

Esperamos que uma vez construído este panorama, seja possível entrever novas linhagens, novas dobras e novas intensidades históricas, questão cara a Benjamin que, ao fim da vida, produziu um ensaio que até hoje tem impactos na compreensão da tarefa da história. Esta edição, deste modo, é o esforço de se somar aos que se interessam pelo exercício de narrar outras histórias, renovadas e muitas vezes, até então, invisíveis.

Desejamos a todos ótimas leituras! 